\title{
The Relationship of Anger Expression to Health Problems Among Black Americans in a National Survey
}

\author{
Ernest H. Johnson ${ }^{1,3}$ and Clifford L. Broman ${ }^{2}$ \\ Accepted for publication: December 8, 1985
}

\begin{abstract}
This study examined the relationship between anger expression, other psychosocial measures, and health problems in a nationally representative, cross-sectional sample of 1277 black adults. Subjects indicating a high level of outwardly expressed anger during a period in which they experienced a severe personal problem had a significantly higher number of health problems than their counterparts who expressed low and moderate levels of anger. Anger expression also significantly interacted with a measure of life strain (employment status) to predict health problems. Blacks who were unemployed were more likely to have a higher number of health problems if anger was expressed outwardly at a high level. The relationship was found to be independent of age, gender, urbanicity, smoking, and drinking problems. The overall pattern of the findings suggests that blacks who are at increased risk for health problems may be identified by how often anger is experienced and expressed during periods of emotional distress.
\end{abstract}

KEY WORDS: anger expression; health; life strain; black Americans.

Research described in this article was supported, in part, by grants from the National Institute of Mental Health, Division of Prevention and Special Programs (Center for Minority Group Mental Health). The National Survey of Black Americans data were collected under the direction of Dr. James S. Jackson. The authors thank him for his support, and for generously allowing use of the data.

${ }^{1}$ Department of Internal Medicine, University of Michigan, Ann Arbor, Michigan 48109-0356. ${ }^{2}$ Department of Sociology, Michigan State University, East Lansing, Michigan.

${ }^{3}$ To whom correspondence should be addressed at Department of Internal Medicine, Division of Hypertension, R6669 Kresge Medical Research Building, University of Michigan Medical School, Ann Arbor, Michigan 48109. 


\section{INTRODUCTION}

Psychosomatic research over the past 40 years has strongly emphasized the relationship between negative emotions and health problems (Alexander, 1939; Dunbar, 1947; Funkenstein et al., 1957; Weiner, 1977; Chesney and Rosenman, 1985). Much attention has been given to research relating anger-hostility to essential hypertension and heart disease (Alexander, 1939; Harburg et al., 1973, 1979; Esler et al., 1977; Diamond, 1982; Johnson, 1984, 1985; Cottington et al., 1985; Julius et al., 1985). Recently, evidence has also begun to mount which suggests that the anger-hostility component of the Type A behavior pattern is the most important coronary-prone behavior (Matthews et al., 1977; Haynes et al., 1978a, b; Dembroski et al., 1986; Williams et al., 1985; Rosenman, 1985).

Investigations of the association between anger-hostility and other health problems have also been carried out and have yielded important findings. For example, a study comparing the psychological attributes of women with malignant breast cancer and benign lumps (Greer and Morris, 1975) showed that these women differed in how they handled their anger. Higher rates of diagnosed breast cancer were found for both women who frequently "suppressed" (anger was reported not to be shown more than once or twice in their lives) and women who frequently "expressed" (anger was reported to be expressed at a high level) their angry-hostile feelings than for women with "normal" emotional response styles. In another study, the "repression" and "denial" of emotional discharge (most often anger and hostility) significantly discriminated patients with lung cancer from general medical controls (Kissen, 1967). Suppressed anger has also been related to diagnosed rheumatoid arthritis (Harburg et al., 1969).

A series of recent studies, both prospective and cross sectional, has found that anger-hostility predicts (1) who will develop coronary heart disease (CHD), (2) which patients will have more severe coronary artery disease, as well as (3) death from CHD and malignant neoplasms, and (4) death from all causes combined (Shekelle et al., 1983; Barefoot et al., 1983). Suppressed hostility (not showing or discussing anger) was also found to be an independent predictor of CHD in men and women in Framingham (Haynes et al., 1980) as well as mortality from all causes in the Tecumseh Community Health Study (Julius et al., 1986).

Although the evidence of a strong association between anger-hostility and health problems is mounting, the subjects in most of the studies cited above have been white males and females. There have been notably few research investigations of the association(s) between anger-hostility and health problems in black Americans. However, the available research, which has focused primarily on hypertension, has found consistent evidence supporting an association among suppressed anger (Harburg et al., 1973, 1979; 
Gentry et al., 1982; Gentry 1985; Johnson, 1984), blood pressure, and hypertension. For example, in the Detroit Study (Harburg et al., 1973), holding-in or suppressing anger-hostility in response to provocation by an angry policeman or landlord was found to be significantly related to elevated blood pressure and hypertension for both black and white residents of highand low-stress neighborhoods.

In a more recent report based on data from the Detroit Study (Gentry et al., 1982), subjects were classified in terms of their habitual anger-coping styles based on their responses to five anger provoking situations. The overall classification of the subjects was made by computing the proportion of "anger-out" responses and then assigning each to a high, medium, or low category of anger expression. The results indicated that subjects in the lowanger (i.e., suppressed anger) expression group had higher blood pressures than their counterparts in the high- and medium-anger expression groups. Important recent findings (Gentry, 1985) have also shown that the pathological relationship between anger expression and elevated blood pressure for subjects in the Detroit Study is mediated by measures of job strain, family strain, and interracial hostility. That is, blacks who had a high level of "life strain" and who tended to "express their anger at a low level" (i.e., suppressed anger) had the highest diastolic blood pressures.

Whereas current research is strongly supportive of a relationship between suppressed anger and hypertension (Diamond, 1982; Julius and Johnson, 1985), it is also clear that expressing anger outwardly is significantly related to blood pressure and hypertension (Gentry et al., 1982; Gentry, 1985; Johnson, 1984; Spielberger et al., 1985) and other health problems (Greer and Morris, 1975). Anger expression is implicitly defined by Harburg et al. (1973), Gentry et al., (1982) and Gentry (1985) as a unidimensional and bipolar construct. In their assessment method, low scores indicate extreme "anger-in," resulting from marked suppression and inhibition of anger, while high scores indicate extreme "anger-out," which may be reflected in a variety of aggressive behaviors. However, it is possible that anger expression is not a unidimensional and bipolar construct. In fact, recent research including more than 2500 respondents (Pollans, 1983; Johnson, 1984; Spielberger et al., 1985) shows that anger-in and anger-out are factorially orthogonal and relatively independent dimensions of anger expression. Whereas both dimensions have been found to be related to blood pressure (Johnson, 1984; Spielberger et al., 1985), the relationships have been stronger for the angerin scale.

In the present inquiry we take the position that the construct of anger expression is best represented by separate dimensions of anger-in and angerout. Ideally, research relating anger to health outcomes should include measures of both dimensions of anger expression as well as measures of the experience (frequency, intensity, and chronicity) of anger. The findings of 
the present investigation were, however, limited to only the anger-out dimension of anger expression. Our primary goal in this article is to describe the association between this dimension of anger expression and health problems in a nationally representative sample of black Americans. Another goal of the present inquiry is to examine the interactions between measures indicative of "life strain" and the frequency that anger is expressed outwardly. The rationale for testing for these interactions is derived from the findings of the Detroit Study (Harburg et al., 1973; Gentry, 1985), which indicated that the relationship between anger expression and hypertension was mediated by similar indicators of life strain. All relationships are tested while statistically controlling for age, gender, urbanicity, and smoking and drinking problems.

\section{MATERIALS AND METHODS}

Subjects. The subjects and data used in this study are from the National Survey of Black Americans (NSBA). The NSBA is the first, nationally representative, cross-sectional sample of the adult (18 years and older) black population. The sample is multistage, area probability one, drawn to ensure that every black household had an equal probability of selection. Special screening procedures were used to ensure location and correct identification of black households. The sampling and interviewing procedures resulted in 2107 completed interviews, which represents a response rate of nearly $70 \%$. More detailed information on the sampling and interviewing procedures is given by Neighbors et al. (1983).

Measures. The measure of anger expression used in this analysis was obtained only for those respondents who reported experiencing a personal problem which caused them to feel that they were at "the point of a nervous breakdown" $(n=1322)$. All subjects responded to a series of items which asked them to report how they responded to the personal problem. Anger items assessed the frequency (very often, fairly often, not too often, hardly ever, never) that anger was expressed outwardly at people and objects in the environment during the period that the respondent experienced the personal problem. This measure consists of three items: (1) Did you lose your temper? (2) Did you fight or argue with other people? and (3) Did it - the personal problem-cause problems in your family life? These items load together on the same factor (.73 to .93) and were found to be highly intercorrelated. It should also be noted that the first two items are identical to items on the Anger-Out subscale of the Anger Expression Scale (see Spielberger et al., 1985). The responses to these items were coded 4 (very often) to 0 (never) and then summed to yield a scale of anger expression. This scale ranges from 
0 to 12 , with a mean of 3.95 , and shows an acceptable level of reliability (alpha $=.74)$. Respondents not answering the anger items were excluded from this analysis $(n=45)$, and thus the working $N$ used in this study is $1277 .{ }^{4}$

Health problems consisted of the number of physician-diagnosed health problems relatively common to black Americans. These items were selected from pretesting in the pilot study for the NSBA data collection. Respondents were asked if a doctor told them that they had any of the following problems: arthritis, ulcers, stroke, nervous condition, circulatory problems, sickle-cell anemia, cancer, hypertension, diabetes, liver or kidney problems, or any other health problems. Responses of "yes" were coded 1 and summed to yield an index of the number of health problems. This index ranges from zero to eight, with a mean of 1.57. Presented in Table I is a list of health problems and the percentage of black adults in the study sample who reported that they had been diagnosed as having the particular health problem. In addition to anger expression, the psychosocial variables examined in this analysis are age, sex, urbanicity, marital status, employment status, and education. Additionally, whether the respondent had been told by a doctor that he had a smoking or drinking problem that is injurious to his health was assessed and treated as a control variable in these analyses. ${ }^{5}$ For purposes of multivariate analysis, the variables sex, urbanicity, marital status, employment status, and smoking and drinking problems were dummy coded, where 1 = male, urban, married, previously married (widowed, divorced, and separated), employed, smoking problems, and drinking problem. In Table II, the distributions of variables used in this study are given.

\section{RESULTS}

Table III presents an intercorrelation matrix of all variables used in the study. With a sample of this size, all correlations larger than .055 are significant at $p<.05$. The first column of results indicates that each variable has an important influence on health problems. Older people, women, rural residents, the nonmarried, the unemployed, and people with low levels of education are more likely to have health problems. Similarly, individuals with excessive smoking and drinking problems (as diagnosed by a physician) are also more likely to have a larger number of health problems than individuals without these problems.

\footnotetext{
${ }^{4}$ The respondents missing from this analyses $(N=830)$ differ demographically from the study sample. They are more likely to be younger, female, highly educated, and nonmarried and to have smoking and drinking problems. However, the relationship between psychosocial factors (excluding anger) and health problems is similar to that of the study sample.

sThe question read, "Have you been told by a doctor that you have a problem with your health because of smoking (drinking)?"
} 
Table 1. Percentage with Specific Health Problem $^{a}$

\begin{tabular}{|c|c|}
\hline Arthritis & 22.7 \\
\hline Ulcers & 14.9 \\
\hline Cancer & 2.9 \\
\hline Hypertension $^{b}$ & 44.3 \\
\hline Diabetes & 10.6 \\
\hline Liver & 3.4 \\
\hline Kidney & 18.1 \\
\hline Stroke & 3.0 \\
\hline Nervous (emotional) condition ${ }^{b}$ & 40.1 \\
\hline $\begin{array}{l}\text { Circulatory problems, arms or } \\
\text { legs }\end{array}$ & 13.5 \\
\hline Sickle cell & 2.8 \\
\hline$N$ & 1277 \\
\hline
\end{tabular}

${ }^{a}$ Respondents could have had more than one health problem.

${ }^{b}$ Excluding this problem from the health index did not significantly alter the findings of the present inquiry.

Table II. Characteristics of the Study Sample

\begin{tabular}{lc}
\hline & $\%$ \\
\hline Age (years) & \\
Less than 30 & 35.9 \\
$30-44$ & 27.7 \\
$45-64$ & 25.8 \\
65 and over & 10.6 \\
Urbanicity & \\
Urban & \\
Rural & 49.5 \\
Sex & 50.5 \\
Male & \\
Female & 33.1 \\
Education (years) & \\
0-8 & \\
9-11 & 19.0 \\
12 & 22.4 \\
13 or more & 31.4 \\
Employment status & 27.2 \\
$\quad$ Employed & \\
Unemployed & 57.2 \\
Marital status & 42.8 \\
Married & \\
Previously married & 39.1 \\
Never married & 38.1 \\
$\quad N$ & 22.9 \\
$\quad N$ & 1277 \\
\hline
\end{tabular}




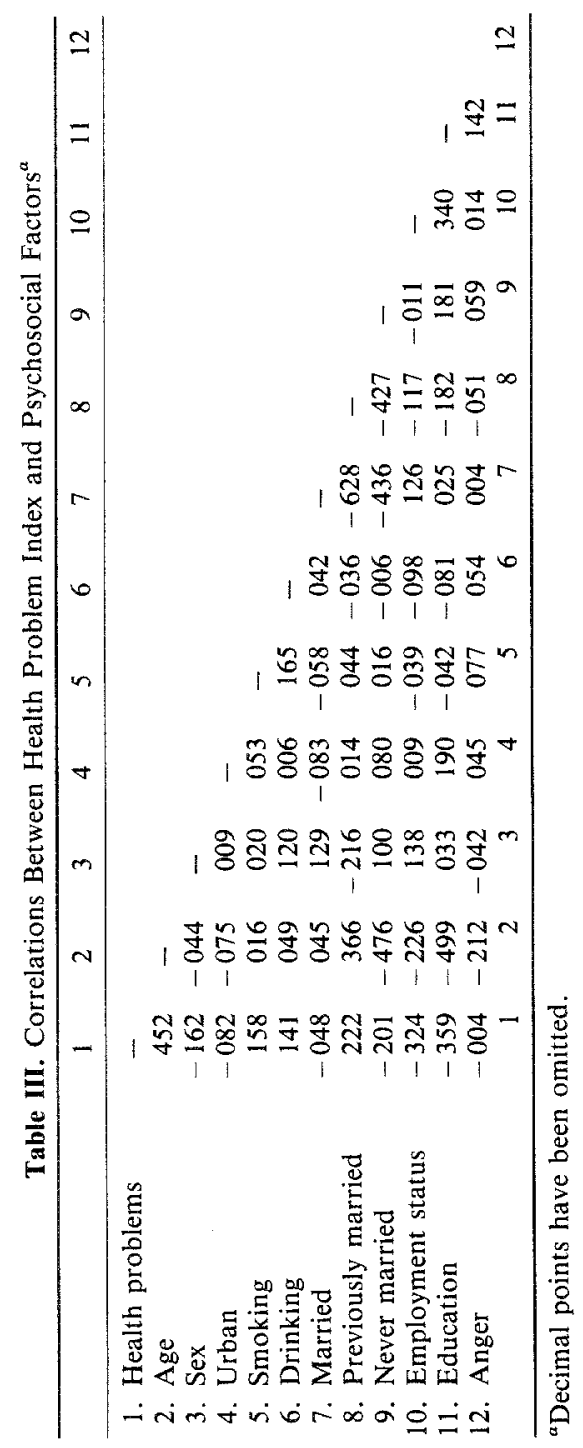


The only variable which is not significantly related to the number of health problems is anger. This result is similar to what previous studies have found, using the data from the Detroit Study (Harburg et al., 1973). In one report using these data (Harburg et al., 1979), anger measures were unrelated to systolic blood pressure and only weakly related to diastolic blood pressure. Anger was, however, significantly related to sociodemographic measures, as is the case here. This suggests that the relationship between anger and health outcomes is suppressed until other variables are controlled for. This result is supported in other reports from the Detroit data. Gentry et al. (1982) reported that once other sociodemographic factors were controlled, anger significantly predicted health outcomes. As we show below, a similar pattern is found in these data. Anger expression is not related to health problems at the zero-order level due to suppression, however, once psychosocial factors are jointly examined, anger is a significant predictor of health problems.

Table IV presents the regression of health problems on psychosocial risk factors. These results are similar to those in Table III, except that some results are shown to be spurious. Age, sex, employment status, education, smoking problem, and drinking problem all have significant effects on health problems. Urbanicity and marital status are not significant predictors of health problems, their relationship being explained away by other variables. We can see that the effect of anger on health problems is significant. People with high anger expression have more health problems, and this relationship exists over and above traditional psychosocial risk factors.

The next stage in the analysis is an examination of possible interactions between anger and other psychosocial risk factors. Interaction terms were created for all possible two-way products. Each term was added to the regression equation to test for the significance of interaction. Only the interaction

Table IV. Regression of Health Problems on Psychosocial Variables

\begin{tabular}{lc}
\hline Constant & .03 \\
Age & $.034^{*}$ \\
Sex & $-.412^{* *}$ \\
Urban & -.140 \\
Smoking & $.732^{* *}$ \\
Drinking & $.726^{* *}$ \\
Married & -.029 \\
Previously married & .075 \\
Employment status & $-.556^{* *}$ \\
Education & $-.050^{* *}$ \\
Anger & $.034^{*}$ \\
$R^{2}$ & .315 \\
\hline${ }^{*} p<.05$. & \\
${ }^{* *} p<.01$. &
\end{tabular}


Table V. Regression of Health Problems on Psychosocial Variables and Interactions

\begin{tabular}{lc}
\hline Constant & .909 \\
Age & $.035^{*}$ \\
Sex & $-.414^{* *}$ \\
Urban & -.140 \\
Smoking & $.719^{* *}$ \\
Drinking & $.707^{* *}$ \\
Married & .027 \\
Previously married & .073 \\
Employment status & $-.349^{* *}$ \\
Education & $-.051^{* *}$ \\
Anger & $.063^{*}$ \\
Anger $\times$ employment status & $-.051^{*}$ \\
$R^{2}$ & .318 \\
\hline${ }^{*} p<.05$. & \\
$* * p<.01$. &
\end{tabular}

between employment status and anger was significant, and these results are presented in Table V. We can see that the relationship between anger and health problems differs across levels of employment status. Specifically, people who are unemployed and who have high anger expression have more health problems. Overall, anger expressed outwardly at a high level was found to have important effects on health among blacks, but life strain/sociodemographic factors play a crucial role in determining those blacks for whom the pathological role of anger has a greater influence on health. These results have important implications for the health of black Americans, which we discuss in the next section.

\section{DISCUSSION}

It has been demonstrated here that anger expression is related to health problems. Another important finding was that blacks who were unemployed were more likely to have health problems if they expressed their anger outwardly at other people at a high level. These findings, which are independent of age, gender, and other traditional risk factors, are remarkably similar to the relationship between high anger-hostility and mortality from all causes that have been reported in previous research (Shekelle et al., 1983; Barefoot et al., 1983). In these two prospective investigations, individuals who had scores in the upper quintile on a measure of anger-hostility (Cook and Medley, 1954) were more likely to die, compared with those who had hostility scores in the lower quintile.

The finding that high levels of expressed anger have detrimental effects on the health of unemployed blacks suggests that high levels of expressed 
anger may be the consequence or cause of high levels of stress and strain. For example, in the Detroit Study (Harburg et al., 1973), black residents who were experiencing a high level of life strain (i.e., residents of high-stress neighborhoods) were more likely to express anger outwardly than black respondents who experienced a low amount of life strain. Furthermore, in one report of the findings from the Detroit Study, persons living in "high stress areas who reported more Anger-Out to an angry boss had the highest blood pressure and this effect appeared to hold more for blacks" (Harburg et al., 1979, p. 198).

There are a number of methodological problems and limitations inherent in the present investigation (and others) which make it difficult to determine the role of anger in health and illness. First, there appears to be much confusion and conceptual ambiguity regarding how the dimensions of anger expression should be defined and considerably more disagreement as to how these dimensions should be measured (Spielberger et al., 1983, 1985; Johnson, 1984). For example, the measure of anger expression used in the present investigation, although different from that of other studies (Harburg et al., 1973, 1979; Baer et al., 1979; Siegel, 1985; Spielberger et al., 1985), tends to be closely related to a "state" or situational assessment of anger expression. Thus, it is possible that these state measures are not necessarily predictive or related to the more enduring tendency or "trait" to express or hold in anger across a wide range of situations.

It is conceivable that for some individuals, expressing anger outwardly at other people as a result of being provoked by a few intense situations (e.g., experiencing a serious personal problem) prolongs and intensifies their emotional and physical (e.g., elevated blood pressure, catecholomines, and cortisol) state, increasing their risk of health problems. For other individuals, it is possible that anger has to be chronically experienced and expressed (or suppressed) to have an influence on the development of health problems. Future research efforts should strongly consider these possibilities and use measures of anger expression that have been validated and are conceptually clear in the dimensions that they assess.

A second major methodological problem inherent in the present investigation is the subjective nature of the respondent-reported health problems. It is quite possible that the self-reports of physician-diagnosed health problems do not correspond to the respondents' objective health status. Although the data of the present investigation do not permit a determination of the association between the respondents' subjective and their objective health status, a review of 39 studies by Ware et al. (1978) has indicated that subjects are highly reliable in their report of health problems. Moreover, these studies have revealed that the individual's subjective and/or reported health status is highly predictive of mortality (LaRue et al., 1979; Maddox 
and Douglas, 1973; Mossey and Shapiro, 1982) and independent of objective health measures.

It is also the case that the mechanisms by which the experience and expression of anger cause health problems are poorly understood, and there is notably little systematic research in this area. For this reason, it is also conceivable that the causal relationship between anger and health problems may be opposite of that proposed. In other words, the experience and expression of anger outwardly at other people may be a reaction to poor health rather than a factor involved in the etiology of health problems. Other investigators (Burish and Bradley, 1983) have documented significant relationships between the increase in both anxiety and depression and the onset or diagnosis of major health problems. This same pattern may also hold true for the association between anger and health problems. However, it is our belief that the pendulum swings in the other direction, with anger being the initial event and the health problems following.

In summary, anger expressed outwardly at other people at a high level was found to be a significant predictor of health problems for a national probability sample of black Americans, and more so for those blacks who were experiencing what we refer to as high levels of life strain (e.g., unemployed). By using an empirically derived measure of one dimension (anger-out) of anger expression, controlling for potential confounders, and examining the interactions of key life-strain measures with anger, some of the limitations of previous investigations were addressed. Therefore, the significant relationships observed cannot be explained by the effects of an unrepresentative sample or certain risk factors for health problems. Nevertheless, certain methodological limitations of the present investigation (and others) that we have discussed indicate specific directions for future research of the relationship(s) between anger and health problems for black Americans. Given that causality is more difficult and, in some cases, impossible to determine in cross-sectional investigations, prospective investigations are needed to evaluate fully the role of anger in physical and emotional health problems for black Americans.

The present investigation also identifies a number of other important areas for future research among black Americans. For example, investigations of the relationshp between anger and objective health status (e.g., CHD, stroke, cancer, hypertension) as well as the relationship between self-reported health problems and objective health are needed. Studies should evaluate the relative importance and interactions of the various dimensions of anger in predicting health problems. It should be noted that there is substantial overlap in the definitions of anger, hostility, and aggression. We have recently (see Spielberger et al., 1985) referred to them collectively as the AHA! syndrome. Anger is generally defined as an emotional state consisting of feel- 
ings of irritation, annoyance, fury, and rage and heightened activation or arousal of the autonomic nervous system (Spielberger et al., 1983, 1985). Hostility also involves angry feelings, but this concept is much broader, usually having the connotation of negative destructive attitudes such as hatred, animosity, and resentment, as well as chronic anger. Aggression generally refers to destructive punitive behaviors directed toward other persons and objects in the environment.

As a first step in the assessment of anger, it is imperative to distinguish between the intensity of the experience of anger as an emotional state (state anger) and individual differences in anger-proneness as a personality trait (trait anger). It is also essential to differentiate between the experience of angry feelings and how these feelings are expressed (anger-out) or suppressed (anger-in). Without such conceptual clarity, it will be impossible to determine fully the biological mechanisms whereby the "deadly dimensions" of the AHA! syndrome are translated into disease processes. Research should also focus on the relationship between the dimensions of the AHA! syndrome and negative health behaviors such as cigarette smoking, alcohol consumption, poor dietary/exercise habits, weight gain/obesity, and Type A behavior. There is also a strong need for reasearch to examine the relationship(s) between the dimensions of anger and certain neuroendocrine measures (e.g., cortisol, catecholamines), cholesterol measures, and immune system functions in black Americans and other subject groups. Sophisticated investigations are needed to determine the consistency of these interactions and the particular biological pathways whereby these factors have a deadly influence on physical and emotional health prior to the implementation of studies directed at the management of the AHA! syndrome.

\section{REFERENCES}

Alexander, F. G. (1939). Emotional factors in essential hypertension: Presentation of a tentative hypothesis. Psychosom. Med. 1: 175-179.

Baer, P. E., Collins, F. C., Bourianoff, G. G., and Ketchell, M. (1979). Assessing personality factors in essential hypertension with a brief self-report instrument. Psychosom. Med. 41: $321-331$.

Barefoot, C. J., Dahlstrom, G. W., and Williams, B. R. (1983). Hostility, CHD incidence and total mortality: A 25-year study of 255 physicians. Psychosom. Med. 45: 59-63.

Burish, T. G., and Bradley, L. A. (1985). Coping with chronic disease. In Burish, T. G., and Bradley, L. A. (eds.), Coping with Chronic Disease: Research and Application, Academic Press, New York.

Chesney, M. A., and Rosenman, R. H. (1985). Anger and Hostility in Cardiovascular and Behavioral Disorders, Hemisphere, McGraw-Hill, New York.

Cook, W. W., and Medley, D. M. (1954). Proposed hostility and pharisaic-Virture scale for the MMPJ. J. Appl. Psychol. 38: 414-418.

Cottington, E. M., Brock, B. M., House, J. S., and Hawthorn, V. M. (1985). Psychosocial factors and blood pressure in the Michigan Statewide Blood Pressure Survey. Am. J. Epidemiol. 121: 515-529. 
Dembroski, T. M., MacDougall, J. M., Williams, R. B., and Haney, T. L. (1986). Components of Type A hositlity and anger-in: Relationship to angiographic findings. Psychosom. Med. (in press).

Diamond, E. L. (1982). The role of anger and hostility in essential hypertension and coronary heart disease. Psychol. Bull. 92: 410-433.

Dunbar, E. (1947). Emotions and Bodily Changes: A Survey of Literature on Psychosomatic Interrelationships, 1910-1945, 3rd ed., Columbia University Press, New York.

Esler, M., Julius, S., Randall, O., Harburg, E., Gardiner, H., and DeQuatro, V. (1977). Mild high-renin essential hypertension: Neurogenic human hypertension? N. Engl. J. Med. 296: 405-411.

Funkeinstein, D. H., King, S. H., and Drolette, M. E. (1954). The direction of anger during a laboratory stress-inducing situation. Psychosom. Med. 16: 404-413.

Gentry, W. D. (1985). Relationship of anger-coping styles and blood pressure among black Americans. In Chesney, M. A., and Rosenman, R. H. (eds.), Anger and Hostility in Cardiovascular and Behavioral Disorders, Hemisphere, McGraw-Hill, New York.

Gentry, W. D., Chesney, A. P., Gary, H. G., Hall, R. P., and Harburg, E. (1982). Habitua] anger-coping styles. I. Effect on mean blood pressure and risk for essential hypertension. Psychosom. Med. 44: 273-281.

Greer, S., and Morris, T. (1975). Psychological attitudes of women who develop breast cancer: A controlled study. J. Psychosom. Res. 19: 147-153.

Harburg, E., Kasl, S. V., and Tabor, J., et al. (1969). Intrafamilial transmission of rheumatoid arthritis. IV. Recalled parent-child relations by rheumatoid arthritis and controls. J. Chron. Dis. 22: 223-239.

Harburg, E., Erfurt, J. C., Hauenstein, L. S. et al. (1973). Sociological stress, suppressed hostility, skin color and black-white male blood pressure: Detroit. Psychosom. Med. 35: 276-296.

Harburg, E., Blakelock, E. H., and Roeper, P. J. (1979). Resentful and reflective coping with arbitrary authority and blood pressure: Detroit. Psychosom. Med. 3: 189-202.

Haynes, S. G., Feinleib, M., Levine, S., Scotch, N., and Kannel, W. B. (1978a). The relationship of psychosocial factors to coronary heart disease in the Framingham Study. 1. Methods and risk factors. Am. J. Epidemiol. 167: 362-383.

Haynes, S. G., Levine, S., Scotch, N., Feinleib, M., and Kannel, W. B. (1978b). The relationship of psychosocial factors to coronary heart desease in the Framingham Study. II. Prevalence of coronary heart disease. Am. J. Epidemiol. 167: 384-402.

Haynes, S. G., Feinleib, M., and Kannel, W. B. (1980). The relationship of psychosocial factors to coronary heart disease in the Framingham Study. III. Eight-year incidence of coronary heart disease. Am. J. Epidemiol. 169: 37-58.

Johnson, E. H. (1984). Anger and Anxiety as Determinants of Blood Pressure in Adolescents: The Tampa Study, Doctoral dissertation, University of South Florida, Tampa.

Johnson, E. H. (1985). Anger expression and hypertension in a national sample of black Americans. Unpublished manuscript, Division of Hypertension, University of Michigan Medical Center, Ann Arbor.

Julius, M., Harburg, E., Cottington, E., and Johnson, E. H. (1986). Anger-coping types, blood pressure, and total mortality: A follow-up in Tecumseh, Michigan, 1971-1983. Am. J. Epidemiol. 124: 220-233.

Julius, S., and Johnson, E. H. (1985). Stress, automatic hyperactivity and essential hypertension: An enigma. J. Hypertens. 3: 11-18.

Julius, S., Schneider, R., and Egan, B. (1985). Suppressed anger in hypertension: Facts and problems. In Chesney, M. A., and Rosenman, R. H. (eds.), Anger and Hostility in Cardiovascular and Behavioral Disorders, Hemisphere, McGraw-Hill, New York.

Kissen, D. M. (1967). Psychological factors, personality and lung cancer in men aged 55-64. B. J. Med. Psychol. 40: 29-43.

LaRue, A., Bank, L., Jarvik, L., et al. (1979). Health in old age: How do physician ratings and self-ratings compare? $J$. Gerontol. 33: 687-691.

Maddox, G. L., and Douglas, E. B. (1973). Self-assessment of health: A longitudinal study of elderly subjects. J. Health Soc. Behav. 14: 89-93.

Matthews, K. A., Glass, D. C., Rosenman, R. H., and Bortner, R. W. (1977). Competitive drive, Pattern A, and coronary heart disease: A further analysis of some data from the Western Collaborative Group Study. J. Chron. Dis. 30: 489-498. 
Mossey, J. M., and Shapiro, E. (1982). Self-rated health: A predictor of mortality among the elderly. Am. J. Publ. Health 72: 800-808.

Neighbors, H. W., Jackson, J. S. Bowman, P. J., and Gurin, G. (1983). Stress, coping and black mental health: Preliminary findings from a national study. Prevent. Hum. Serv. 2: $5-29$

Pollans, C. H. (1983). The Psychometric Properties and Factors Structure of the Anger Expression Scale, Master's thesis, University of South Florida, Tampa.

Rosenman, R. H. (1985). Health consequences of anger and implications for treatment. In Chesney, M. a., and Rosenman, R. H. (eds.), Anger and Hostility in Cardiovascular and Behavioral Disorders, Hemisphere, McGraw-Hill, New York.

Shekelle, R. B., Gale, M. Ostfeld, M. A., and Paul, O. (1983). Hostility, risk of CHD, and mortality. Psychsom. Med. 45: 109-114.

Siegel, J. M. (1985). Anger and cardiovascular risk in adolescents. Health Psychol. 3: 293-313.

Spielberger, C. D., Jacobs, G., Russell, S., and Crane, R. (1983). Assessment of anger: The State-Trait Anger Scale. In Butcher, J. N., and Speilberger, C. D. (eds.), Advances in Personality Assessment, Vol. 2, Lawrence Earlbaum, Hillsdale, N.J.

Spielberger, C. D., Johnson, E. H., Russell, S. F., Crane, R., Jacobs, G. A., and Worden, T. J. (1985). The experience and expression of anger: Construction and validation of an anger expression scale. In Chesney, M. A., and Rosenbaum, R. H. (eds.), Anger and Hostility in Cardiovascular and Behavioral Disorders, Hemisphere, McGraw-Hill, New York.

Ware, J. E., Davies-Avery, A., and Donald, C. A. (1978). Conceptualization and Measurement of health for Adults in the Health Insurance Study: Vol. V, General Health Perceptions, Rand Corp., Santa Monica, Calif.

Weiner, H. (1977). Psychobiology and Human Disease, Elsevier-North Holland, New York.

Williams, R. B., Barefoot, J. C., and Shekelle, R. B. (1985). The health consequences of hostility. In Chesney, M. A., and Rosenman, R. H. (eds.), Anger and Hostility in Cardiovascular and Behavioral Disorders, Hemisphere, McGraw-Hill, New York. 